\title{
\begin{tabular}{l|l|l} 
& Jurnal Kependidikan Dasar & Volume. 2 \\
Nomor. 1 \\
Tahun. 2017
\end{tabular}
}

\section{Pendidikan Islam Indonesia dan Tantangan Globalisasi: Perspektif Sosio-Historis}

\author{
Djulaiha Gaus \\ Dosen STKIP Kie Raha Ternate \\ the.djulaiha55@gmail.com
}

\begin{abstract}
Abstrak
Tantangan nasional dan global yang dihadapi oleh pendidikan Islam semakin kompleks, khususnya di Indonesia di era global ini, dihadapkan pada problematika filosofis-sosial yang tidak kunjung usai. Ada dua masalah yang dihadapi oleh pendidikan Islam pada tantangan Globalisasi. 1). Sebagai peluang, (globalisasi) satu sisi akan memudahkan pendidikan Islam untuk mengakses berbagai informasi dengan mudah. Juga memudahkan pendidikan Islam untuk menyebarluaskan (diseminasi) produk-produk keilmuan yang memberikan manfaat seluas-luasnya bagi masyarakat. 2). Sebagai tantangan, ternyata globalisasi tidak hanya mempengaruhi tatanan kehidupan pada tataran makro, tetapi juga mengubah tata kehidupan pada tataran mikro, misalnya terhadap ikatan kehidupan sosial masyarakat. Yaitu, Fenomena disintegrasi sosial, hilangnya nilai-nilai tradisi, lunturnya adat-istiadat, sopan santun, dan penyimpangan sosial lainya Dalam tulisan ini, berkesimpulan bahwa, lembaga-lembaga pendidikan Islam secara keseluruhan tetap menjalankan perannya dalam tiga hal pokok: transmisi ilmu-ilmu dan pengetahuan Islam (transmission of Islamic knowlwdge); kedua, pemeliharaan tradisi Islam (maintenance of Islamic tradition); ketiga, kaderisasi calon-calon ulama. Peserta didik tidak hanya menggetahui ilmu-ilmu agama, atau sebaliknya tidak hanya mengetahui pengetahuan umum, dengan demikian, dapat melakukan mobilisasi pendidikan. Disamping itu, para anak didik memiliki keterampilan, keahlian atau life skills khususnya dalam bidang sains dan teknologi yang menjadi karakter dan ciri globalisasi, yang pada gilirannya membuat mereka memiliki dasar-dasar dalam lapangan kerja sebagaimana dituntut di alam globalisasi.
\end{abstract}

Kata kunci: pendidikan, Islam, Globalisasi. 


\begin{abstract}
National and global challenges faced by the Islamic education is increasingly complex, particularly in Indonesia in this global era, faced with problems of social-philosophical failed over. There are two problems faced by Islamic education on the challenges of globalization. 1.) as an opportunity, (globalization) one side will make it easier for Islamic education to access a variety of information easily. Also makes it easier to disseminate Islamic education (dissemination) Scientific products that deliver the benefits of existence for the society.2.) as a challenge, it turns out that globalization not only affects the order of life on a macro level, but also change the life at the micro level, for example against the bond of the social life of the community. That is, the phenomenon of social disintegration, the loss of values tradition, lunturnya customs, manners, and other social deviation in this paper, concludes that, Islamic institutions as a whole still run his role in three basic:the transmission of knowledge and the Sciences of Islam. Secondly, maintenance of Islamic tradition; third, the reproduction of the candidates.
\end{abstract}

Keywords: Education, Islam, Globalization.

\section{A. PENDAHULUAN}

Berbicara mengenai masalah pendidikan Agama, mulai dari lembaga perguruan tinggi, pesantren, maupun madrasah di era globalisasi, harus dilihat dalam konteks pendidikan Islam.Tinjauan tersebut, baik dalam perjalanan sejarah maupun dinamika pendidikan Islam kontemporer, tantangan nasional dan global yang dihadapi oleh pendidikan Islam semakin kompleks. Pendidikan Islam, khususnya di Indonesia di era global ini, dihadapkan pada problematika filosofis-sosial yang tidak kunjung usai. Berbagai wacana maupun tawaran yang muncul, baik dari kalangan pendidik maupun dari pemerhati dan peneliti pendidikan Islam sekalipun. Ini dimaksudkan untuk menyelesaikan masalah yang krusial ini mulai dari normatif hingga historis.

Namun, semua wacana dan tawaran tersebut dapat dikatakan belum memadai. Sehingga, masih tetap saja menyisakan persoalan yang belum jelas tanpa dibarengi dengan penyelesaiannya.Untuk itu, masyarakat Muslim dalam meningkatkan kecintaannya terhadap Islam, membuat banyak kalangan semakin berusaha mendapatkan pendidikan Islam yang berkualitas. Keinginan mereka untuk mendapatkan pendidikan Islam yang berkualitas tinggi, dimana peserta didik tidak hanya mendapatkan ilmu-ilmu untuk kehidupan masa kini saja, tetapi juga ilmuilmu dan amal Islam untuk kedepannya.

Oleh karena itu, tulisan ini mencoba menguraikan pendidikan Islam dalam menghadapi tantangan di era globalisasi ini. Tidak hanya unggul dalam ilmu agama saja, melainkan dapat unggul di setiap lini ilmu-ilmu pengetahuan umum lainnya.

\section{B. PENDIDIKAN ISLAM DALAM TINJAUAN SEJARAH}

Umat Islam dalam catatan sejarah, sesungguhnya telah memperlihatkan betapa pentingnya peran pendidikan dalam proses perkembangan umat 
manusia. Hal ini, dapat ditelusuri sejak masa Rasulullah Saw hingga dewasa saat ini.Kegiatan-kegiatan yang dilakukan Rasulullah, seperti mengadakan ta'lim (pembelajaran) kepada para sahabatnya untuk mengetahui ajaran-ajaran Islam dengan dibentuknya, atau membuat kelompok-kelompok belajar, bila diera moder saat ini maka dikenal dengan istilah study club.Sebagai contoh atau bukti dari kesungguhan Rasulullah dalam membina umat Islam dikala itu adalah dengan adanya forum belajar yang selalu dilaksanakanantara rasulullah dan para sahabat-sahabatnya, melalui forum Dar Alarqam, hal ini merupakan salah satu bukti perhatian Rasulullah terhadap pendidikan ${ }^{1}$. Bagi nabi Muhammad, pendidikan sangatlah penting untuk pengembangan umat Islam, sehingga dikatan olehnya bahwa "ilmu itu peroleh dengan belajar, ${ }^{2}$ maka tidak heran jika forum-forum belajar perlu untuk selalu dilestarikan bila sudah ada, dan jika belum terbentuk maka berusaha untuk dibentuk agar proses pendidikan mampu berjalan dengan baik.

Kondisi aktivitas belajar baru mengalami perubahan yang berarti ketika Islam lahir.Bagi bangsa Arab, masjid merupakan lembaga pendidikan pertama yang bersifat umum dan sistematis.Di masjidlah, anak-anak dan orang dewasa, baik laki-laki maupun perempuan menuntut ilmu.Usaha pendidikan ini, kemudian ditindak lanjuti oleh para generasi berikutnya.Pendidikan dan

\footnotetext{
${ }^{1}$ Suwendi, Sejarah Dan Pemikiran Pendidikan Islam (Jakarta: RajaGrafindo Persada, 2004), 171-72.

${ }^{2}$ Raghib As-Sirjani and Al-Madari Amir, "Spiritual Reading Hidup Lebih Bermakna Dengan Membaca," Solo: Aqwam, 2007, 143.
}

pengajaran terus tumbuh dan berkembang pada masa khulafaurrasyidin dan masa Bani Umayyah.Pada masa Abbasyiah pendidikan dan pengajaran berkembang pesat di seluruh Negara Islam. Sehingga lahir madrasah-madrasah yang tidak terhitung jumlahnya, mulai dari kota hingga ke desa-desa. ${ }^{3}$

Dalam sejarah Islam di Indonesia, tumbuh dan berkembangnya ajaran Islam tidak lepas dari jalannya proses pendidikan yang terjadi pada masa itu. menurut Azra dalam Burhanudin dan Afrianty, Meski pendidikan Islam merupakan pendidikan yang sesungguhnya universal dan merakyat bagi masyarakat Muslim Indonesia, secara historis bagian terbesar sejarah pendidikan Islam adalah sejarah tentang keterpinggiran dan marjinalisasi. Dalam masa penjajahan Belanda, pendidikan Islam berpusat pada pesantren, surau, dayah, dan lembaga-lembaga pendidikan lain semacamnya, yang terutama berkembang luas sejak abad ke 19, bahkan sengaja menguzlahkan diri dari kekuasaan kolonial. ${ }^{4}$

1. Pesantren

Poerbakawatja mengatakan, bahwa pesantren berasal dari kata santri, yaitu seorang yang belajar agama Islam, sehingga dengan demikian, pesantren memiliki arti tempat orang berkumpul untuk belajar agama Islam. ${ }^{5}$ Pesantren merupakan

\footnotetext{
${ }^{3}$ Ibid., 173-74.

${ }^{4}$ Jajat Burhanuddin and Dina Afrianty, "Mencetak Muslim Modern: Peta Pendidikan Islam Indonesia" (Jakarta: PT Raja Grafindo Persada, 2016), 2, http://www.repository.uinjkt.ac.id/dspace/handle/1234 56789/32552.

${ }^{5}$ Soegarda Poerbakawatja and others, Ensiklopedi Pendidikan (Jakarta: Gunung Agung, 1976), 233.
} 
lembaga pendidikan Islam yang masih bersifat tradisional, yang dijadikan sebagai wadah dalam pengembangan Islam. Sebagaimana dikatakan oleh Ronald Alan dan Lukens Bull, mereka mengklasifikasikan pesantren menjadi dua macam yaitu pesantren yang tradisional (salafiyyah) dan pesantern modern. ${ }^{6}$

Pesantren tradisional dapat dipahami sebagai pesantren yang memelihara bentuk pengajaran teks klasik dan pendidikan moral sebagai inti pendidikan-nya. Sedangkan pesantren modern dapat dipahami sebagai pesantren yang mengajarkan pelajaran-pelajaran umum disamping pelajaran-pelajaran agama dan pendidikan moral.

2. Surau

Surau merupakan lembaga pendidikan Islam di Minangkabau, Azra dalam Nizar mengatakan, Surau di Minangkabau sudah dikenal sebelum datangnya Islam.Surau dalam sistem adat Minangkabau adalah kepunyaan suku atau kaum sebagai pelengkap rumah gadang yang berfungsi sebagai tempat bertemu, berkumpul, rapat, dan tempat tidur bagi anak laki-laki yang telah aqil baligh dan orang tua yang uzur. ${ }^{7}$

Fungsi surau tidak berubah setelah kedatangan Islam, Pada masa itu, eksistensi surau di samping sebagai tempat shalat juga digunakan

\footnotetext{
${ }^{6}$ L. B. Ronald, "Jihad Ala Pesantren Di Mata Antropolog Amerika," Yogyakarta: Gama Media, 2004, 5-6.

${ }^{7}$ Samsul Nizar, Sejarah Pendidikan Islam: Menelusuri Jejak Sejarah Pendidikan Era Rasulullah Sampai Indonesia (Jakarta: Kencana, 2007), 280.
}

sebagai tempat mengajarkan ajaran Islam.Sebagai lembaga pendidikan tradisional, materi pendidikan yang diajarkan pada awalnya masih belajar seputar huruf hijaiyah, al-Quran, keimanan, akhlak dan ibadah.

3. Masjid

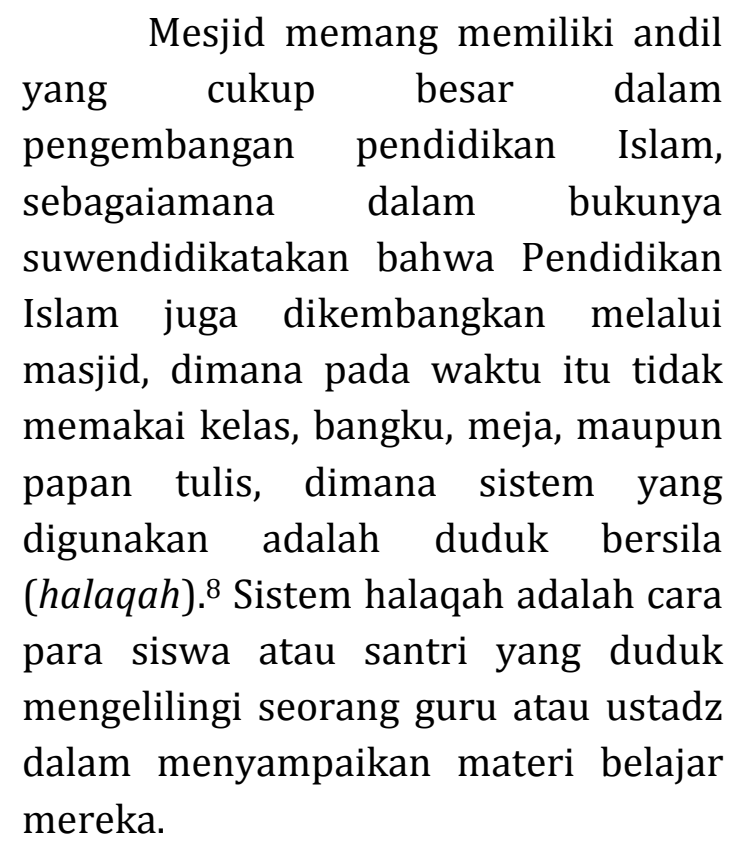

Sementara untuk pendidikan formal Islam, sebagaimana dikatakan Azra baru muncul pada masa lebih belakangan, yakni dengan kebangkitan madrasah. ${ }^{9}$ Stanton, dalam Azra, menyebut madrasah sebagai the instution of higher learning artinya, lembaga keilmuan/pendidikan tinggi. Lebih jauh dikatakan, dalam tradisi pendidikan Islam, institusi pendidikan tinggi lebih dikenal dengan namaalJami'ah, yang tentu secara historis dan kelembagaan berkaitan dengan masjid jami' atau dikenal dengan masjid besar, yang digunakan sebagai tempat

\footnotetext{
${ }^{8}$ Suwendi, Sejarah Dan Pemikiran Pendidikan Islam, 175.

${ }^{9}$ Azyumardi Azra, Pendidikan Islam Tradisi Dan Modernisasi Di Tengah Tantangan Milenium III (Jakarta: Kencana, 2012), v.
} 
berkumpul jama'ah untuk menunaikan shalat jum'at. 10

Konsep pendidikan Islam, pada dasarnya sangat mementingkan sumber daya manusia yang berkualitas, baik kualitas bersifat duniawi maupun ukhrawi secara integral. Ariefin, sebagaimana dikutip Idi \& Suharto, mengatakan pada dasarnya tujuan pendidikan Islam adalah merealisasikan Muslim yang beriman, bertakwa, dan berilmu pengetahuan, serta mengabdi kepada-Nya. ${ }^{11}$

Oleh karena itu, pendidikan Islam dalam sejarahnya, yang dimulai dari masa Rasulullah, Khulafaurrasyudin, hingga sekarang ini, tidak lepas dari tantangantantangan yang dapat merubah ruang lingkup pendidikan Islam sendiri.Tantangan global ini, memang tidak bisa dipungkiri, disebabkan perkembangan zaman yang semakin modern sudah barang tentu style, pola hidup masyarakat pun berbeda.

\section{GLOBALISASIDAN PENDIDIKAN ISLAM.}

Globalisasi berasal dari bahasa Inggris, asal katanya global yang berarti mendunia. ${ }^{12}$ Era globalisasi, dewasa ini dan mendatang, terus mempengaruhi perkembangan sosial budaya masyarakat Muslim Indonesia umumnya, atau pendidikan Islam pada khususnya. Itu sebabnya, masyarakat Muslim tidak dapat menghindari diri dari proses globalisasi tersebut. Padahal, Pendidikan Islam

\footnotetext{
${ }^{10}$ Ibid., vi.

${ }^{11}$ Abdullah Idi and Toto Suharto, Revitalisasi

Pendidikan Islam (Yogyakarta: Tiara Wacana, 2006), 139.

${ }^{12}$ John M. Echols, Kamus Inggris Indonesia (Jakarta: Gramedia, 2005), 270.
}

bertujuan untuk membentuk pribadi muslimseutuhnya, mengembangkan seluruh potensi manusia baik yang berbentuk jasmaniah maupun rohaniah, menumbuhsuburkan hubungan yang harmonis setiap pribadi dengan Allah, manusia, dan alam semesta. ${ }^{13}$

Di sisi lain, pendidikan Islam diharapkan mampu mengatasi dan menyelesaikan krisis multidimensial yang dihadapi bangsa ini, terutama yang menyangkut aspek moral, etika, dan sekaligus hendak memberikan kontribusi dalam menjabarkan pendidikan nasional yang berfungsi mengembangkan kemampuan dan membangun watak serta beradaban bangsa yang bermartabat dalam rangka mencerdaskan kehidupan bangsa. Ini bertujuan, untuk berkembangnya potensi peserta didik agar menjadi manusia yang beriman dan bertakwa kepada Tuhan Yang Maha Esa, berakhlak mulia, sehat, berilmu, cakap, Kreatif, mandiri, dan menjadi warga Negara yang demokratis serta bertanggung jawab. ${ }^{14}$

Akan tetapi, konsep di atas mendapatkan tantangan baru bersamaan dengan bergulirnya era globalisasi. Globalisasi berasal dari kata dasar "global" yang berarti seluruhnya; menyeluruh, garis besar, umumnya, secara utuh. Globalisasi perspektif terminologis ialah pengglobalan seluruh aspek kehidupan; perwujudan secara menyeluruh di segala

\footnotetext{
${ }^{13}$ Syahrin Harahap, "Perguruan Tinggi Islam Di Era Globalisasi," Yokyakarta: Tiara Wacana, 1998, 123.

${ }^{14}$ Depdiknas, "Undang-Undang RI No 20 Tahun 2003 Tentang Sisdiknas (Sistem Pendidikan Nasional)" (Depdiknas, 2013).
} 
aspek kehidupan. ${ }^{15}$ Itu sebabnya, Globalisasi, jika kita mengacu kepada penjelasan Azyumardi Azra, bukanlah fenomena baru sama sekali bagi masyarakat Muslim di Indonesia. Sejak akhir abad 19 dan awal abad 20 sumber globalisasi datang dari Timur Tengah yang bersifat religio-intelektual, meskipun dalam kurun-kurun tertentu juga diwarnai oleh semangat religio-politik. ${ }^{16}$

Untuk itu, globalisasi lebih dapat dipahami dari pesefektif di atas adalah condong kepada modernisasi. Oleh karenanya, Kerangka dasar modernisasi pendidikan Islam secara keseluruhan adalah bahwa modernisasi pemikiran dan kelembagaan Islam, merupakan prasyarat bagi kebangkitan kaum muslim dimasa modern. Oleh karenanya, menurutnya pemikiran dan kelembagaan Islam, termasuk pendidikan,haruslah dimodernisasi,atau dalam bahasa sederhana diperbaharui sesuai dengan kerangkamodernitas, mempertahankan pemikiran kelembagaan Islam tradisionalhanya akan memperpanjang nestapa ketidakberdayaan kaum muslim dalamberhadapan dengan kemajuan dunia modern.

Di dalam Oxford Advanced Learner's Dictionary of Current English sebagai mana yang dikutif oleh Idi \& Suharto, disebutkan bahwa istilah globalisasi berasal dari kata global yang dalam bahasa inggris berarti embracing the whole of a group of items (merangkul keseluruhan kelompok yang

\footnotetext{
${ }^{15}$ Pius A. Partanto and M. Dahlan Al Barry, Kamus Ilmiah Populer (Surabaya: Arkola, 2001), 203.

${ }^{16}$ Azyumardi Azra, Pendidikan Islam: Tradisi Dan Modernisasi Menuju Milenium Baru (Jakarta: Logos Wacana Ilmu, 1999), 43.
}

ada). ${ }^{17}$ Oleh karena itu, dapat disimpulkan bahwa dalam globalisasi terdapat saling ketergantungan dalam masalah-masalah sosial, politik dan kultural antar bangsa. Artinya, perkembangan perikehidupan sosial, cultural, dan politik suatu bangsa akan saling mengait dengan bangsa lainnya.

Ketika globalisasi dihadapkan dengan pendidikan Islam, terselip dua implikasi sekaligus, yakni peluang dan tantangan. Zubaedi menjelaskan:

1. Sebagai peluang, (globalisasi) satu sisi akan memudahkan pendidikan Islam untuk mengakses berbagai informasi dengan mudah. Juga memudahkan pendidikan Islam untuk menyebarluaskan (diseminasi) produk-produk keilmuan yang memberikan manfaat seluas-luasnya bagi masyarakat.

2. Sebagai tantangan, ternyata globalisasi tidak hanya mempengaruhi tatanan kehidupan pada tataran makro, tetapi juga mengubah tata kehidupan pada tataran mikro, misalnya terhadap ikatan kehidupan sosial masyarakat. Fenomena disintegrasi sosial, hilangnya nilai-nilai tradisi, lunturnya adat-istiadat, sopan santun, dan penyimpangan sosial lainya. ${ }^{18}$

Pada sisilain, dari dampak negatif globalisasi ialah pemiskinan spiritual. Keringnya nilai-nilai religiusitas tercermin dari perubahan cara pandang terhadap kehidupan kemasyarakatan. Misalnya, tindakan sosial yang tidak mempunyai

\footnotetext{
${ }^{17}$ Idi and Suharto, Revitalisasi Pendidikan Islam, 102.

${ }^{18}$ Zubaidi, Isu-Isu Baru Dalam Diskursus Filsafat Pendidikan Islam Dan Kapita Selekta Pendidikan Islam, (Yogyakarta: Pustaka Pelajar, 2012), 54.
} 
implikasi materi (tidak produktif), dianggap sebagai tindakan yang tidak rasional.

Kalau mengacu pada persoalan di atas, seperti yang dikatakan Zainuddin, bahwa pengaruh globalisasi, modernitas mempunyai andil besar dalam merubah gaya dan pola hidup (life style) pada hampir semua lapisan hidup masyarakat, termasuk masyarakat Muslim. Sehingga, tidak bisa dipungkiri bahwa anak-anak belajar nilai kebanyakan dari budaya popular dan media massa. ${ }^{19}$

Dari fenomena di atas, pengaruh globalisasi menyebabkan tantangan dalam dunia pendidikan di Indonesia.Tantangan itu tidak hanya dialami dalam pendidikan Nasional saja, melainkan termasuk dalam pendidikan Islam.Untuk itu, Muhaimin ${ }^{20}$ mengatakan bahwa bangsa Indonesia sedang menghadapi tantangan yang berat, terutama dalam konteks pendidikan yang diakibatkan oleh pengaruh globalisasi, diantaranya:

a. Globalisasi di bidang budaya, etika, moral, sebagai akibat dari kemajuan teknologi di bidang transformasi dan informasi. Para peserta didik saat ini telah mengenal berbagai sumber pesan dan media pembelajaran, baik yang dapat dikontrol maupun yang sulit dikontrol.

b. Rendahnya tingkat sosial-capital, diman esensi dari sosial capital adalah trust (sikap amanah). Menurut

\footnotetext{
${ }^{19}$ Muhammad Zainuddin, Paradigma Pendidikan Terpadu, Menyiapkan Generasi Ulul Albab (Malang: UIN Malang Press, 2013), 2-3.

${ }^{20}$ Muhaimin, Rekonstruksi Pendidikan Islam: Dari Paradigma Pengembangan, Manajemen, Kelembagaan, Kurikulum Hingga Strategi Pembelajaran (Jakarta: Rajawali Press, 2009), 15-17.
}

pengamatan semetara para ahli, bahwa dalam bidang sosial capital bangsa Indonesia hampir mencapai titik "zero trust society", atau masyarakat yang sulit dipercaya, berarti sikap amanah yang sangat lemah.

c. Diberlakukannya globalisasi dan perdagangan bebas, berarti persaingan alumni dalam pekerjaan semakin ketat.

d. Tenaga asing meningkat, sedangkan tenaga Indonesia yang dikirim keluar negeri pada umumnya nonprofesional.

Oleh karena itu, dari uraian di atas, ada dua event yang hampir bersamaan munculnya pada saat bangsa Indonesia memasuki milenium ketiga.Pertama globalisasi, diakibatkan kemajuan ilmu dan teknologi terutama komunikasi dan transportasi sehingga dunia semakin menjadi tanpa batas. Dalam budaya global ini ditandai dalam bidang ekonomi perdagangan akan menuju terbentuknya pasar bebas, baik dalam kawasan ASEAN, Asia Pasifik bahkan akan meliputi seluruh dunia. Dalam bidang politik akan tumbuh semangat demokratisasi.

Dalam bidang budaya akan terjadi pertukaran budaya antarbangsa yang berlangsung begitu cepat yang saling mempengaruhi, dalam bidang sosial akan muncul semangat konsumeris yang tinggi disebabkan pabrik-pabrik yang memproduksi kebutuhan konsumeris akan berupaya memproduk barangbarang baru yang akan bertukar dengan cepat pada setiap saat dan merangsang manusia untuk memilikinya.

Event kedua adalah reformasi, dalam era reformasi ini diharapkan akan muncul Indonesia baru. Wajah baru 
Indonesia ini akan memunculkan perbedaan yang kontras dengan wajah lamanya. Wajah baru Indonesia itu adalah wajah baru yang akan memunculkan masyarakat madani, yakni masyarakat berperadaban dengan menekankan kepada demokratisasi dan hak-hak asasi manusia.

\section{RESPON PENDIDIKAN ISLAM}

Kalau melihat pengaruh globalisasi dan tantangan yang masyarakat Indonesia terutama dalam konterks pendidikan di atas, pendidikan Islam mau tidak mau harus terlibat dalam mengatasi dan menyelesaikan berbagai persoalan dan tantangan tersebut bersama dengan kekuatan-kekuatan pendidikan nasional yang lain. Bahkan, tidak hanya itu ditopang juga dengan kekuatan sosial, politik, dan ekonomi pada umumnya. Hanya saja pendidikan Islam, perlu melakukan evaluasi diri terlebih dahulu kemudian selanjutnya melakukan reaktualisasi dan reposisi, dengan cara melakukan singkronisasi dengan kebijakan pendidikan nasional untuk membebaskan bangsa dari berbagai persoalan di atas.

Selain itu, dalam merespon tantangan global di atas, yang secara implisit mengakomodasi hampir semua keseluruhan harapan masyarakat secara sekaligus kepada pendidikan Islam, sebagaimana dikatakan Azra, dalam Buhanuddin \& Afrianty ${ }^{21}$ yaitu:

1. Harapan pertama, agar lembagalembaga pendidikan Islam secara

\footnotetext{
${ }^{21}$ Burhanuddin and Afrianty, "Mencetak Muslim Modern," 13.
}

keseluruhan tetap menjalankan perannya dalam tiga kal pokok: pertama, transmisi ilmu-ilmu dan pengetahuan Islam (transmission of Islamic knowledge); kedua, pemeliharaan tradisi Islam (maintenance of Islamic tradition); ketiga, reproduksi calon-calon ulama.

2. Harapan kedua, agar peserta didik tidak hanya menggetahui ilmu-ilmu agama, atau sebaliknya tidak hanya mengetahui pengetahuan umum, dengan demikian, dapat melakukan mobilisasi pendidikan.

3. Harapan ketiga, agar para anak didik memiliki keterampilan, keahlian atau life skills khususnya dalam bidang sains dan teknologi yang menjadi karakter dan ciri globalisasi, yang pada gilirannya membuat mereka memiliki dasar-dasar dalam lapangan kerja sebagaimana dituntut di alam globalisasi.

Untuk itu, dalam menghadapi tantangan global, pendidikan Islam secara realistis, harus disingkronisasikan dengan kebijakan pendidikan nasional guna membebaskan bangsa ini dari himpitan persoalan yang dihadapi saat ini. Dengan demikian, tulis A. Malik Fadjar22 ada beberapa hal mengenai prinsip-prinsip strategis pengembangan, antara lain:

a. Orientasi pengembangan sumber daya, dalam pengertian ini maka pendidikan Islam harus berfungsi sebagai anticipatory learning isnstitutions, dan dengan ketersediaan sumberdaya

\footnotetext{
${ }^{22}$ Muhammad Zainuddin and Muhammad In'am Esha, Horison Baru Pengembangan Pendidikan Islam, Upaya Merespon Dinamika Masyarakat Global (Malang: UIN Malang Press, 2004), xxii.
} 
manusia yang tangguh, yang berwujud manusia-manusia yang cerdas secara intlektual, sosial dan spiritual. Bahkan, memiliki dedikasi dan disiplin, jujur, tekun, ulet dan inovatif.

b. Ke arah pendidikan Islam multikulturalis, dalam masyarakat dalam negeri maupun internasional, yang demikian majemuk, pendidikan Islam perlu dikemas dalam watak multikultural, ramah menyapa, perbedaan budaya, sosial dan agama.Hal demikian cukup beralasan, Realitas multikultural merupakan sebuah keniscayaan yang tidak bisa dihindari lagidi indonesia. Melihat fakta bahwa indonesia memilki keragaman etnik, budaya, bahasa agama, gender, ras, usia, dan kelas sosial. $^{23}$

Karena selama ini pendidikan Islam baik sebagai lembaga pendidikan maupun sebagai materi, oleh pengamat pendidikan Islam di Indonesia dikritik karena telah mempraktikkan proses pendidikan yang eksklusif, dogmatik dan kurang menyentuh aspek moralitas.

Mempertegas misi dasar "li Utammima Makarima al-Akhlaq". Ketika dunia mengalami perubahan dan perkembangan demikian dahsyat, segala bidang dan lapangan kehidupan peradaban dapat menonjolkan watak manipulatifnya.

a. Spiritualisasi watak kebangsaan fondasi dari banguna kebangsaan itu

\footnotetext{
${ }^{23}$ AHMAD SULTHON and others, "KURIKULUM PESANTREN MULTIKULTURAL (Melacak Muatan Nilai-Nilai Multikultural Dalam Kurikulum Pondok Pesantren Sunan Drajat Banjarwati Paciran Lamongan)" (UNIVERSITAS ISLAM NEGERI SUNAN KALIJAGA, 2014), 2, http://digilib.uinsuka.ac.id/id/eprint/15120.
}

menurut persepektif Islam adalah Iman.

\section{E. Kesimpulan}

Dari uraian singkat di atas, dapat ditarik benang merah bahwa dalam sejarahnya pendidikan Islam, mulai dari masa lahirnya Islam sampai sekarang ini, yang terutama di Indonesia, secara historis bagian terbesar sejarah pendidikan Islam, adalah sejarah tentang keterpinggiran dan marjinalisasi. Tantangan Ini terbukti dari perlawanan bangsa belanda dan jepang selama berada di Negara ini.

Selain itu, pengaruh globalisasi dewasa ini dan mendatang, terus mempengaruhi perkembangan sosial budaya masyarakat Muslim Indonesia umumnya, atau pendidikan Islam pada khususnya. Globalisasi mempunyai andil besar dalam merubah gaya dan pola hidup (life style) pada hampir semua lapisan hidup masyarakat, termasuk masyarakat Muslim. Kemajuan ilmu dan teknologi terutama komunikasi dan transportasi sehingga dunia semakin menjadi tanpa batas. Dalam budaya global ini ditandai dalam bidang ekonomi perdagangan akan menuju terbentuknya pasar bebas, baik dalam kawasan ASEAN, Asia Pasifik bahkan akan meliputi seluruh dunia. Dalam bidang politik akan tumbuh semangat demokratisasi.

Untuk itu, untuk merespon tantangan di atas, pendidikan Islam perlu melakukan evaluasi diri terlebih dahulu, kemudian selanjutnya melakukan reaktualisasi dan reposisi, dengan cara melakukan singkronisasi dengan kebijakan pendidikan nasional untuk 
membebaskan bangsa dari berbagai persoalan di atas. Selain itu, ketersediaan sumberdaya manusia yang tangguh, yang berwujud manusia-manusia yang cerdas secara intlektual, sosial dan spiritual.Bahkan, memiliki dedikasi dan disiplin, jujur, tekun, ulet dan inovatif.Serta Mempertegas misi dasar "li Utammima Makarima al-Akhlaq".

\section{F. DAFTAR REFERENSI}

As-Sirjani, Raghib, and Al-Madari Amir.

"Spiritual Reading Hidup Lebih

Bermakna Dengan Membaca." Solo: Aqwam, 2007.

Azra, Azyumardi. Pendidikan Islam Tradisi

Dan Modernisasi Di Tengah

Tantangan Milenium III. Jakarta:

Kencana, 2012.

-—- Pendidikan Islam: Tradisi Dan Modernisasi Menuju Milenium Baru. Jakarta: Logos Wacana Ilmu, 1999. Burhanuddin, Jajat, and Dina Afrianty. "Mencetak Muslim Modern: Peta Pendidikan Islam Indonesia." Jakarta: PT Raja Grafindo Persada, 2016.

http://www.repository.uinjkt.ac.id /dspace/handle/123456789/3255 2.

Depdiknas. “Undang-Undang RI No 20 Tahun 2003 Tentang Sisdiknas (Sistem Pendidikan Nasional)." Depdiknas, 2013.

Echols, John M. Kamus Inggris Indonesia. Jakarta: Gramedia, 2005.

Harahap, Syahrin. "Perguruan Tinggi Islam

Di Era Globalisasi." Yokyakarta:

Tiara Wacana, 1998.

Idi, Abdullah, and Toto Suharto. Revitalisasi Pendidikan Islam. Yogyakarta: Tiara Wacana, 2006.

Muhaimin. Rekonstruksi Pendidikan Islam: Dari Paradigma Pengembangan,
Manajemen, Kelembagaan, Kurikulum Hingga Strategi Pembelajaran. Jakarta: Rajawali Press, 2009.

Nizar, Samsul. Sejarah Pendidikan Islam: Menelusuri Jejak Sejarah Pendidikan Era Rasulullah Sampai Indonesia. Jakarta: Kencana, 2007.

Partanto, Pius A., and M. Dahlan Al Barry. Kamus Ilmiah Populer. Surabaya: Arkola, 2001.

Poerbakawatja, Soegarda, and others. Ensiklopedi Pendidikan. Jakarta: Gunung Agung, 1976.

Ronald, L. B. "Jihad Ala Pesantren Di Mata Antropolog Amerika." Yogyakarta: Gama Media, 2004.

SULTHON, AHMAD, and others. "KURIKULUM PESANTREN MULTIKULTURAL (Melacak Muatan Nilai-Nilai Multikultural Dalam Kurikulum Pondok Pesantren Sunan Drajat Banjarwati Paciran Lamongan)." UNIVERSITAS ISLAM NEGERI SUNAN KALIJAGA, 2014. http://digilib.uinsuka.ac.id/id/eprint/15120.

Suwendi. Sejarah Dan Pemikiran Pendidikan Islam. Jakarta: RajaGrafindo Persada, 2004.

Zainuddin, Muhammad. Paradigma Pendidikan Terpadu, Menyiapkan Generasi Ulul Albab. Malang: UIN Malang Press, 2013.

Zainuddin, Muhammad, and Muhammad In'am Esha. Horison Baru Pengembangan Pendidikan Islam, Upaya Merespon Dinamika Masyarakat Global. Malang: UIN Malang Press, 2004.

Zubaidi. Isu-Isu Baru Dalam Diskursus Filsafat Pendidikan Islam Dan Kapita Selekta Pendidikan Islam,. Yogyakarta: Pustaka Pelajar, 2012. 